\title{
Effect of pharmaceutical care on clinical outcomes of outpatients with type 2 diabetes mellitus
}

This article was published in the following Dove Press journal:

Patient Preference and Adherence

8 May 2017

Number of times this article has been viewed

\author{
Hua Shao' \\ Guoming Chen' \\ Chao Zhu ${ }^{2}$ \\ Yongfei Chen' \\ Yamin Liu' \\ Yuxing $\mathrm{He}^{2}$ \\ Hui Jin ${ }^{3}$

\begin{abstract}
'Department of Pharmacy,
Zhongda Hospital, School of

Medicine, Southeast University,

${ }^{2}$ Department of Clinical Pharmacy,

China Pharmaceutical University,

${ }^{3}$ Department of Endocrinology,

Zhongda Hospital, School of Medicine,

Southeast University, Nanjing, People's

Republic of China
\end{abstract}

\begin{abstract}
Background: In the People's Republic of China, outpatients have limited time with their physicians. Thus, compared to inpatients, outpatients have lower medication adherence and are less knowledgeable about their disease.

Objective: The objective of this study was to evaluate the effect of pharmaceutical care on clinical outcomes of outpatients with type 2 diabetes mellitus (T2DM).

Patients and methods: A randomized, controlled, prospective clinical trial was conducted recruiting a total of 240 T2DM outpatients from Zhongda Hospital, Southeast University. The control group (CG) received only common care from medical staff, whereas the intervention group (IG) received extra pharmaceutical care from clinical pharmacists. Biochemical data such as blood pressure (BP), fasting blood glucose (FBG), glycosylated hemoglobin A1 (HbA1c), and blood lipid were collected before and after 6-month intervention. The primary end points in this study were FBG and HbA1c.
\end{abstract}

Results: After the intervention, most of the baseline clinical outcomes of the patients in IG significantly improved, while only body mass index, diastolic BP, low-density lipoprotein cholesterol, and total cholesterol (TC) improved significantly in patients in the CG. Compared to $\mathrm{CG}$, in IG, there were significant improvements in FBG, HbAlc, TC, the target attainment rates of $\mathrm{HbAlc}$, and $\mathrm{BP}$.

Conclusion: Pharmaceutical care provided by clinical pharmacists could improve the control of diabetes of outpatients, and clinical pharmacists could play an important role in diabetes management.

Keywords: clinical pharmacist, pharmaceutical care, type 2 diabetes, outpatients

\section{Introduction}

Type 2 diabetes mellitus (T2DM) is a lifelong incurable metabolic disease with an increasing prevalence worldwide. The latest data from the International Diabetes Federation showed that the global prevalence of diabetes has reached 371 million in 2012 and is still undergoing a rapid increase. ${ }^{1}$ In 2011, there were 90 million diabetic patients in the People's Republic of China, and the number is predicted to reach 130 million in 2030. Furthermore, 480 million people die from diabetes and treatment cost for diabetes has exceeded 471 billion every year.

Pharmaceutical care provided by clinical pharmacists is defined as "the responsible provision of drug therapy for the purpose of achieving definite outcomes that improve a patient's quality of life". ${ }^{2}$ It has been proven to be useful and helpful in improving the medication quality for both ambulatory and hospitalized patients with various diseases such as hypertension, ${ }^{3}$ asthma, ${ }^{4}$ dyslipidemia, ${ }^{5}$ heart failure, ${ }^{6}$ and tuberculosis. ${ }^{7}$ In particular relevance to diabetes, some studies have suggested that
Correspondence: Hua Shao

Department of Pharmacy, Zhongda Hospital, School of Medicine, Southeast University, 87 Dingjiaqiao Road, Nanjing 210009, People's Republic of China Email gycsh@I63.com 
pharmaceutical care can not only facilitate good glycemic control and reduce cardiovascular risk but also gain a favorable cost-effectiveness. ${ }^{8-10}$

Clinical pharmacists have been playing an important role in the People's Republic of China in recent years, providing pharmaceutical care for an expanding population of patients with cardiovascular diseases, ${ }^{11}$ cancer, ${ }^{12}$ respiratory diseases,${ }^{13}$ and so on. Although some studies reported pharmaceutical care in endocrinal diseases, ${ }^{14}$ a major limitation is that few research were conducted on outpatients. This is of particular concern, especially in the People's Republic of China, since a large population of outpatients generally have limited time with their physicians. In this study, we performed a prospective clinical trial to evaluate the effect of pharmaceutical care on T2DM outpatients.

\section{Patients and methods}

This study was approved by the Medical Ethics Committee on Human Research (Institutional Review Board) at Zhongda Hospital, Southeast University. Patients provided written informed consent to participate in this study.

\section{Study design}

This study was a randomized, controlled, prospective trial with 6-month follow-up. Patients were recruited from the endocrinology outpatient service of Zhongda Hospital, Southeast University (Nanjing, People's Republic of China). Patients diagnosed with $\mathrm{T}_{2} \mathrm{DM}^{15}$ were recruited into this study and screened based on the inclusion criteria (ie, 18 years old and above, 3-month duration of diabetes or longer, taking at least one anti-diabetic medication, receiving oral hypoglycemic therapy for over 3 months, and willingness to cooperate and regularly visit the hospital) and exclusion criteria (ie, mental disorders or incapable of communication; other types of diabetes; pregnancy; comorbidity of cancer, organ failure, or other severe diseases; macroalbuminuria $>300 \mathrm{mg} / 24 \mathrm{~h}$ ). After recruitment, patients were randomly assigned to intervention group (IG) or control group (CG). CG patients received only usual care from medical staff, whereas IG patients received an extra pharmaceutical care from a clinical pharmacist. The primary end points in this study included fasting blood glucose (FBG) and glycosylated hemoglobin (HbAlc).

\section{Sample size}

The sample size calculation based on variability of $\mathrm{HbA} 1 \mathrm{c}$ in T2DM is $n=2 *\left(U_{\alpha}+U_{\beta}\right)^{2} \delta^{2} / d^{2}$. With $\alpha=0.01$ and power of $0.90(\beta=0.1)$, a sample size of $n=84$ of each group was required. As there might be "dropouts" during the study
(20\%), a target sample size of 200 (100 patients for CG and 100 for IG) was selected.

\section{Pharmaceutical care interventions}

The intervention program included diabetic education and interviews. All patients in the IG were educated twice in this study (at the beginning and the third month, respectively) on basic knowledge of T2DM, risk of diabetes complications, proper use and precautions of oral antidiabetics and insulin, signs or symptoms of hypoglycemia and self management, appropriate self blood glucose monitoring, and healthy lifestyle. Interviews included face-to-face interview (once every other month) and telephone follow-up (once a month) till the end of this study. During the interview, pharmacist discussed with each patient about their medication adherence, self-monitoring of glycemic control, exercise; explained the side effects of drugs and possible drug interactions; and reminded them of their next visit as scheduled. After the interview, individual medical history files were maintained for each patient.

\section{Data collection}

The height, weight, blood pressure (BP), FBG, postprandial blood glucose 2h (PBG2h), HbA1c, blood lipid levels (triglyceride [TG], total cholesterol [TC], high-density lipoprotein cholesterol [HDL-c], and low-density lipoprotein cholesterol [LDL-c]) according to physician's order were collected from hospital information system before and after 6-month follow-up. Medication adherence was assessed by the Morisky Green Levine Scale ${ }^{16}$ during interview, which consists of four questions: 1) Have you ever forgotten to take medication? 2) Are you careless at times about taking your medicine? 3) Do you sometimes stop taking your medicine when you feel better? 4) Sometime if you feel worse when you take medicine, do you stop taking it? Patients got either one or zero score when they answered "yes" or "no" to each question. For each patient, scores ranged from zero to four, in which zero stands for high adherence and four stands for nonadherence. Self-designed Personal General Questionnaire was used to investigate the general condition of patients, such as gender, age, working status, education level, course of disease, payment of medical expenses, complications, and so on.

\section{Statistical analysis}

Statistical Package for the Social Sciences (SPSS) 11.5 was used for statistical analysis, and the data were expressed as mean \pm standard deviation. Differences between control and intervention groups were evaluated using independent $t$-test and differences between baseline and endpoint outcome 
measures were determined using the paired $t$-test. $P<0.05$ was considered statistically significant.

\section{Results}

\section{Patient disposition}

A total of 450 patients were preliminarily assessed and finally 240 patients were recruited. A total of 120 patients were randomized into each group after strict screening. Among them, 199 patients completed this study; 20 and 21 patients dropped out from IG and CG, respectively (Figure 1). The basic characteristics of the two groups are presented in Table 1. Results showed that the two groups had no significant differences in most of the baseline parameters $(P>0.05)$, except the payment made toward medical treatment. Biochemical indices, especially HbA1c, BP, FBG, HDL-c, LDL-c, TG and TC, had no significant difference and were comparable between the two groups before the intervention, as shown in Table 2.

\section{Clinical outcome measurements}

As shown in Table 2, both the primary end points FBG $(P<0.05)$ and HbAlc $(P<0.05)$ decreased significantly after 6-month intervention in IG, while no significant changes were observed in CG. The ratio of patients who reached the target HbAlc level $(<7 \%)$ in the IG increased to $76.0 \%$, which was significantly higher than that of CG $(47.5 \%, P<0.05)$ and that of IG before intervention $(57.0 \%, P<0.05)$ (Table 2 and Figure 2).

The mean body mass index (BMI) decreased significantly $(P<0.05)$ in both groups after 6-month follow-up. However, there was no statistical significance of BMI between the two groups after intervention $(P>0.05)$.

At baseline, the BP values of IG were slightly higher than that of $\mathrm{CG}$, but both systolic blood pressure (SBP) and diastolic blood pressure (DBP) decreased significantly $(P<0.05)$, and the ratio of patients who reached standard levels ( $\leq 130 / 80 \mathrm{mmHg}$ ) increased from $47 \%$ to $71 \%$ after the intervention. In contrast, no significant change was seen in the SBP values of CG $(P>0.05)$ and DBP increased significantly compared with baseline values $(P<0.05)$, as shown in Table 2 and Figure 3. The values of urinary protein/ creatinine in both groups decreased after 6-month follow-up, but neither showed statistical significance within or between groups $(P>0.05)$.

In terms of lipid profiles, HDL-c, TG, and TC decreased significantly in IG compared to baseline levels $(P<0.05)$, except LDL-c $(P>0.05)$. In the CG, the levels of LDL-c and TC increased significantly $(P<0.05)$, while TG and HDL-c showed only mild increase $(P>0.05)$. No significant change was found between these two groups in all lipid profiles after pharmaceutical care.

\section{Medication adherence}

The baseline scores of both groups showed a comparable medication adherence (Table 2). After intervention, IG had a significantly greater medication adherence than $\mathrm{CG}(P<0.05)$, while the adherence score of $\mathrm{CG}$ did not show a significant change $(P>0.05)$ before and after 6-month follow-up.

\section{Multiple regression analysis of influencing factors of $\mathrm{HbAlc}$}

A multiple regression analysis was undertaken to analyze the factors that may affect $\mathrm{HbA1c}$. The results showed that duration of diabetes in years, values of baseline $\mathrm{HbAlc}$, and scores of adherence after 6 months were predominant influencing factors. Every 1 year increase in disease course is linked to $0.03 \%$ increase in $\mathrm{HbA} 1 \mathrm{c}$ level while every 1 point increase in

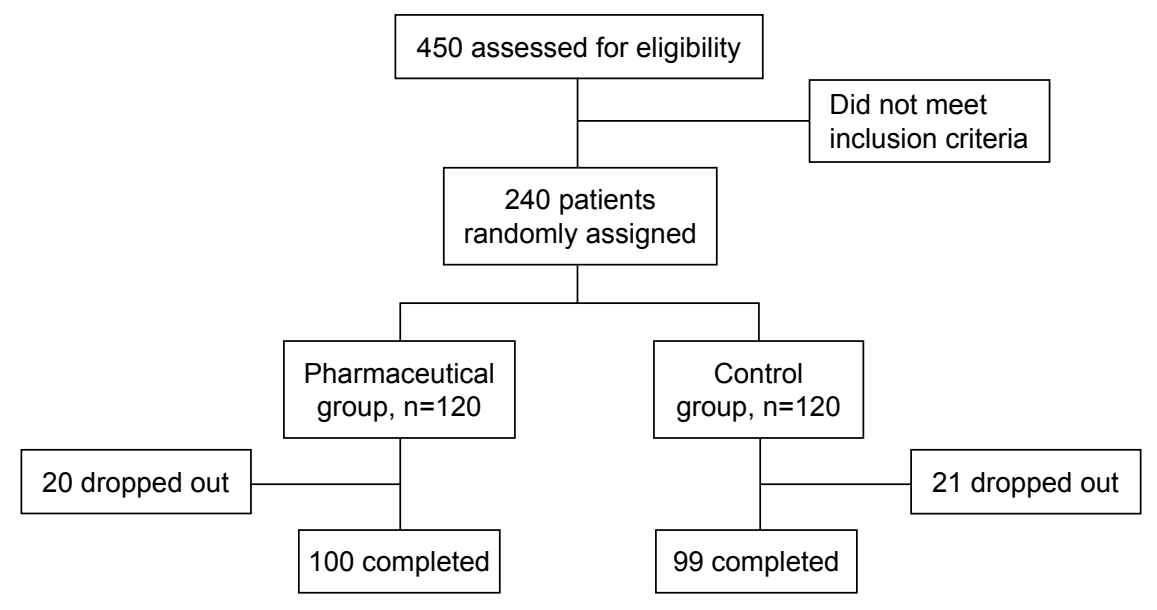

Figure I Flowchart of participants' screening for this study. 
Table I Baseline demographics and clinical characteristics of participants

\begin{tabular}{|c|c|c|c|c|}
\hline Demographics & Levels & IG $(n=100)$ & CG $(n=99)$ & P-value \\
\hline Mean age (year) & & $58.86 \pm 10.59$ & $59.20 \pm 10.34$ & 0.818 \\
\hline Male, n (\%) & & $5 \mathrm{I}(5 \mathrm{I} .0 \%)$ & 47 (47.5\%) & 0.619 \\
\hline \multirow[t]{4}{*}{ Level of education } & None & $4(4.0 \%)$ & $5(5.2 \%)$ & 0.929 \\
\hline & Primary & $2(2.0 \%)$ & $3(3.1 \%)$ & \\
\hline & Secondary & $63(63.0 \%)$ & 58 (58.5\%) & \\
\hline & Bachelor and above & 31 (31.0\%) & 30 (31.3\%) & \\
\hline \multirow[t]{2}{*}{ Working status } & No & $62(62.0 \%)$ & $56(56.5 \%)$ & 0.435 \\
\hline & Yes & $38(38.0 \%)$ & 43 (43.4\%) & \\
\hline \multirow[t]{3}{*}{ Medical expense } & Medical insurance & 81 (8I.0\%) & $59(59.6 \%)$ & 0.003 \\
\hline & Public insurance & 12 (12.0\%) & 21 (2I.2\%) & \\
\hline & Private expense & 7 (7.0\%) & $19(19.2 \%)$ & \\
\hline BMI $\left(k g / m^{2}\right)$ & & $24.87 \pm 3.34$ & $24.32 \pm 3.14$ & 0.235 \\
\hline Duration of diabetes (year) & & $7.86 \pm 6.61$ & $8.22 \pm 6.10$ & 0.690 \\
\hline \multirow[t]{2}{*}{ Family history of diabetes } & Yes & $46(46.0 \%)$ & $53(53.5 \%)$ & 0.288 \\
\hline & No & $54(54.0 \%)$ & 46 (46.5\%) & \\
\hline \multirow[t]{2}{*}{ Complications } & Yes & $35(35.0 \%)$ & $27(27.3 \%)$ & 0.239 \\
\hline & No & 65 (65.0\%) & 72 (72.7\%) & \\
\hline \multirow[t]{2}{*}{ Smoking } & Yes & $35(35.0 \%)$ & 33 (33.3\%) & 0.804 \\
\hline & No & $65(65.0 \%)$ & $66(66.7 \%)$ & \\
\hline \multirow[t]{2}{*}{ Alcohol drinking } & Yes & $2 \mathrm{I}(2 \mathrm{I} .0 \%)$ & $26(26.3 \%)$ & 0.382 \\
\hline & No & 79 (79.0\%) & 73 (73.7\%) & \\
\hline \multirow[t]{2}{*}{ Exercise } & Yes & 70 (70.0\%) & 77 (77.8\%) & 0.212 \\
\hline & No & 30 (30.0\%) & $22(22.2 \%)$ & \\
\hline Number of prescribed medications & & $4.23 \pm 2.13$ & $3.8 I \pm 2.07$ & 0.155 \\
\hline
\end{tabular}

Note: Data presented as $\mathrm{n}(\%)$ or mean \pm standard deviation.

Abbreviations: BMI, body mass index; CG, control group; IG, intervention group; SD, standard deviation.

scores of adherence after intervention result in $0.47 \%$ increase in HbAic level, as shown in Table 3.

\section{Discussion}

In this controlled, prospective clinical trial, we found that the levels of FBG, HbAlc, BP, HDL, TG, TC, BMI, and medication adherence significantly improved in IG, while those in CG had no improvement. These results provide clinical evidences that pharmaceutical care has a positive role in T2DM management and suggest that routine participation of clinical pharmacists in medical teams for outpatients is of high therapeutic value.

Table 2 Comparison of clinical indices before and after the intervention

\begin{tabular}{|c|c|c|c|c|c|c|c|c|}
\hline \multirow[t]{2}{*}{ Variables } & \multicolumn{2}{|l|}{ IG $(n=100)$} & \multicolumn{2}{|l|}{ CG $(n=99)$} & \multirow[t]{2}{*}{$P$-value ${ }^{a}$} & \multirow[t]{2}{*}{$P$-value ${ }^{b}$} & \multirow[t]{2}{*}{$P$-value ${ }^{c}$} & \multirow[t]{2}{*}{$P$-value } \\
\hline & Before & After & Before & After & & & & \\
\hline $\mathrm{FBG}(\mathrm{mmol} / \mathrm{L})$ & $7.34 \pm 2.25$ & $6.26 \pm 1.00$ & $7.45 \pm 2.45$ & $7.73 \pm 1.71$ & 0.844 & $<0.001$ & $<0.001$ & 0.205 \\
\hline $\mathrm{HbAlc}(\%)$ & $7.38 \pm 1.7 \mid$ & $6.69 \pm 0.77$ & $7.37 \pm I .44$ & $7.46 \pm 1.11$ & 0.996 & $<0.001$ & $<0.001$ & 0.410 \\
\hline $\mathrm{SBP}(\mathrm{mmHg})$ & $131.99 \pm 16.96$ & $|27.58 \pm| 2.56$ & $|30.00 \pm| 6.8 \mid$ & $129.46 \pm 12.89$ & 0.416 & 0.298 & $<0.001$ & 0.529 \\
\hline $\mathrm{DBP}(\mathrm{mmHg})$ & $82.15 \pm 9.14$ & $80.25 \pm 6.29$ & $80.05 \pm 9.13$ & $81.55 \pm 6.50$ & 0.080 & 0.155 & 0.018 & 0.014 \\
\hline HDL-c (mmol/L) & $\mathrm{I} .4 \mathrm{I} \pm 0.33$ & $1.30 \pm 0.28$ & $1.35 \pm 0.39$ & $1.35 \pm 0.33$ & 0.711 & 0.326 & $<0.001$ & 0.774 \\
\hline LDL-c (mmol/L) & $3.00 \pm 0.83$ & $2.88 \pm 0.76$ & $2.93 \pm 0.85$ & $3.10 \pm 0.79$ & 0.418 & 0.108 & 0.123 & 0.027 \\
\hline $\mathrm{TG}(\mathrm{mmol} / \mathrm{L})$ & $1.63 \pm 1.35$ & $1.39 \pm 0.93$ & $1.53 \pm 0.77$ & $1.58 \pm 0.77$ & 0.465 & 0.187 & 0.040 & 0.459 \\
\hline $\mathrm{TC}(\mathrm{mmol} / \mathrm{L})$ & $5.03 \pm 1.00$ & $4.79 \pm 0.94$ & $4.90 \pm 1.08$ & $5.15 \pm 1.08$ & 0.282 & 0.048 & 0.013 & 0.006 \\
\hline BMI $\left(\mathrm{kg} / \mathrm{m}^{2}\right)$ & $24.87 \pm 3.34$ & $24.46 \pm 3.14$ & $24.31 \pm 3.13$ & $24.14 \pm 3.10$ & 0.562 & 0.473 & $<0.001$ & $<0.001$ \\
\hline $\begin{array}{l}\text { The urine protein/creatinine } \\
(\mathrm{mg} / \mathrm{g})\end{array}$ & $29.91 \pm 48.74$ & $27.4 I \pm 40.80$ & $36.39 \pm 57.58$ & $31.05 \pm 45.58$ & 0.183 & 0.722 & 0.427 & 0.337 \\
\hline $\begin{array}{l}\text { Patients who achieved HbAlc } \\
\text { target of }<7 \%\end{array}$ & $57(57.0)$ & $76(76.0)$ & $49(49.5)$ & $47(47.5)$ & 0.289 & $<0.001$ & $<0.001$ & 0.864 \\
\hline Patients who achieved BP target & $47(47.0)$ & 7I (7I.0) & $46(46.5)$ & $52(52.5)$ & 0.940 & 0.007 & $<0.001$ & 0.168 \\
\hline Scores of adherence & $0.70 \pm 0.78$ & $0.65 \pm 0.77$ & $0.11 \pm 0.32$ & $0.68 \pm 0.77$ & 0.718 & 0.047 & $<0.001$ & 0.770 \\
\hline
\end{tabular}

Notes: Data presented as $\mathrm{n}(\%)$ or mean \pm standard deviation. ${ }^{a} \mathrm{G}$ versus CG before intervention; 니 versus CG after intervention; cbefore versus after intervention of IG; before versus after intervention of CG.

Abbreviations: BMI, body mass index; BP, blood pressure; CG, control group; DBP, diastolic blood pressure; FBG, fasting blood glucose; HbAIc, glycosylated hemoglobin AI; HDL-c, high-density lipoprotein cholesterol; IG, intervention group; LDL-c, low-density lipoprotein cholesterol; SBP, systolic blood pressure; SD, standard deviation; TG, triglyceride; TC, total cholesterol. 


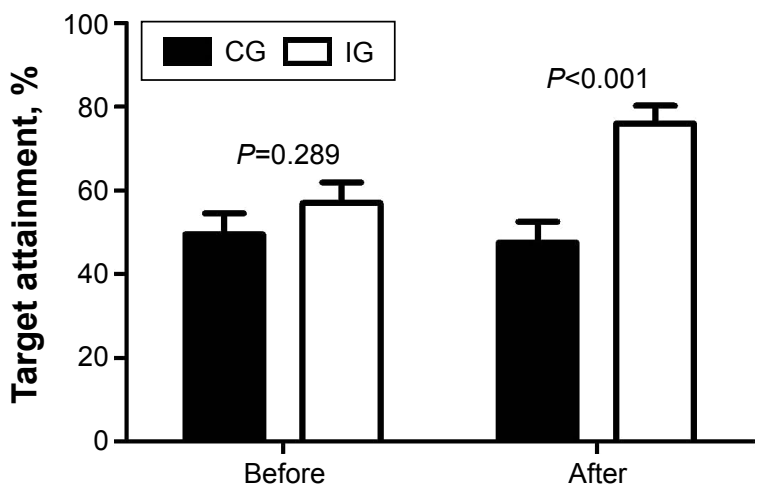

Figure 2 Target HbAlc attainment of both groups before and after the intervention.

Abbreviations: CG, control group; HbAlc, glycosylated hemoglobin AI; IG, intervention group.

Poor adherence, including medication adherence and lifestyle adjustment adherence, can greatly influence the treatment outcomes. ${ }^{17}$ In a number of reasons that may affect adherence, the most common but overlooked issue is the extent to which patients may understand the medical plan. ${ }^{18}$ Ciechanowski et al found that better communication between patients and clinicians contributed to a better compliance and more desirable glycemic control. ${ }^{19}$ Miller pointed out that education could improve patients' adherence by intervening their behavior and lifestyle, by enhancing the communication between patients and their physicians, and by other strategies. ${ }^{17}$ In Obreli-Neto et al study, 36 months of pharmaceutical care was given to elderly patients with diabetes and high BP, and the results showed that the compliance of IG increased from $50.5 \%$ at baseline to $83.5 \%{ }^{20}$ Similarly, Al Mazroui et al also found that after 12 months of pharmaceutical care, the compliance of diabetes patients was significantly improved and increased from $51.3 \%$ to $78.6 \%$. Our study also confirmed this observation in outpatients with T2DM. Together, these findings support that through the active participation of clinical pharmacists, the adherence

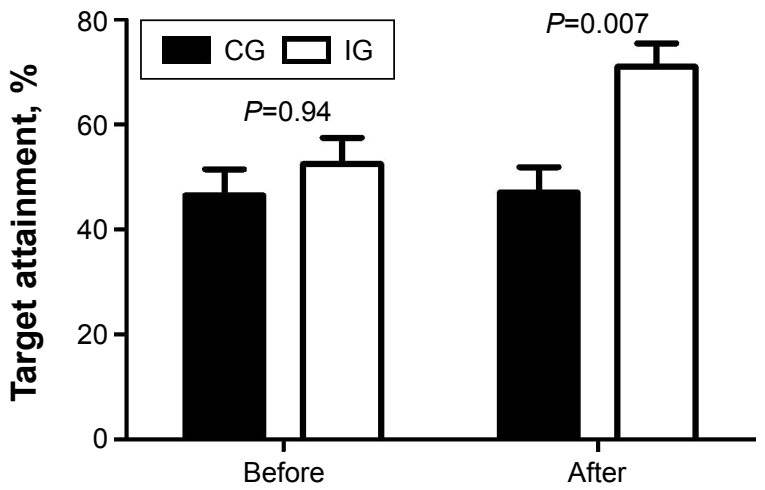

Figure 3 Target blood pressure attainment of both groups before and after the intervention.

Abbreviations: CG, control group; IG, intervention group.
Table 3 Multiple regression analysis on the influencing factors of $\mathrm{HbAlc}$

\begin{tabular}{llll}
\hline Variables & Coefficient & $\begin{array}{l}\text { Standardized } \\
\text { coefficient }\end{array}$ & P-value \\
\hline Constant & 5.10 & 0.00 & $<0.001$ \\
Age & -0.01 & -0.10 & 0.188 \\
Gender & $-0.1 \mathrm{I}$ & -0.05 & 0.403 \\
Duration of diabetes & 0.03 & 0.18 & 0.007 \\
$\begin{array}{l}\text { Values of baseline HbAIc } \\
\text { Scores of adherence }\end{array}$ & 0.34 & 0.52 & $<0.00$ I \\
before the intervention & -0.09 & -0.07 & 0.274 \\
$\begin{array}{l}\text { Scores of adherence } \\
\text { after the intervention }\end{array}$ & 0.47 & 0.28 & $<0.00$ I \\
Level of education & -0.04 & -0.04 & 0.468 \\
Working status & -0.05 & -0.08 & 0.342 \\
\hline
\end{tabular}

Notes: Regression equation: $F=\mid 4.027, P<0.001, R=0.639$.

Abbreviation: $\mathrm{HbAlc}$, glycosylated hemoglobin Al.

of diabetic patients could be significantly improved and thereafter the clinical outcomes.

In this study, many biochemical indices of IG showed a significant improvement, such as FPG, HbA1c, BP, lipids, and BMI, which may be attributed to the improvement of patients' adherence, solving and preventing some medicationrelated problems. There is a close relationship among good compliance, good glycemic control, and well-improved clinical indices. ${ }^{21-23}$ In this study, multiple regression analysis showed that there is an inverse linear relationship between $\mathrm{HbAlc}$ values and adherence.

Most of the clinical indices of CG showed no significant improvement after 6 months. The possible reasons are as follows: first, with a longer duration of diabetes and progressive deterioration of pancreatic $\beta$-cell function, the disease will progress, which would make more difficult to control blood glucose levels. The UKPDS34 study found that $\mathrm{HbAlc}$ of the conventional treatment group continued to rise over the duration of treatment, but $\mathrm{HbA} 1 \mathrm{c}$ of the intensive therapy group also showed a continued upward trend with the extension of treatment, even though blood glucose levels were well controlled at the initial stages of randomized treatment. ${ }^{24}$ The ADOPT study published recently also showed that glycemic control in patients showed a gradual worsening trend with prolonged disease. ${ }^{25}$ In this study, the progression of diabetes may be the major reason why the conventional treatment group showed no significant improvement. Second, patients of this study had poor adherence score at baseline, and T2DM is commonly associated with comorbid conditions such as hypertension and cardiovascular and cerebrovascular disease. A long-term poor adherence to treatment regimens is very likely to affect the control of patients' blood glucose, $\mathrm{BP}$, and so on. Third, the laboratory indices should deteriorate with the disease progression if no treatment was initiated, 
which means that conventional therapy could slow down the progression to some degree.

This study found that the mean HbA1c level decreased significantly after 6-month intervention, which is consistent with other studies. Obreli-Neto et $\mathrm{al}^{20}$ and Borges et $\mathrm{al}^{26}$ found that the mean HbA1c level significantly decreased by $0.9 \%$ and $0.7 \%$, respectively, after the intervention of pharmaceutical care. However, Odegard et al showed that there was no obvious difference in improving HbAlc after the intervention of pharmaceutical care. ${ }^{27}$ In Odegard et al's study, clinical pharmacists provided only consulting services for the IG and did not work together with clinicians as a whole medical team, which might contribute to the unfavorable results of clinical pharmacist's interventions.

This study also found a positive conclusion on the effect of pharmaceutical care on the control of hypertension in patients with diabetes. At the end of the study, $71 \%$ of patients in IG had their BP in control $(<130 / 80 \mathrm{mmHg})$, while in CG only $52.5 \%$ had their BP in control. Considering that patients with hypertension in both groups were taking similar effective antihypertensive treatments, this result may be attributed to the improvement of compliance and adjustment of lifestyle. ${ }^{28,29}$

The current study has several limitations. First, the Morisky Green Levine Scale is a self-report test and therefore subjective questionnaire, which might affect the objectiveness of adherence score. Second, 6-month follow-up is a relatively short time period, and biochemical indices were collected only at the end of this study. It would have been better if a study with longer follow-up was conducted, and data were collected at several different time points. Lastly, the current study focused on outpatient; therefore, our study may not be well extrapolated to the overall diabetic patients.

\section{Conclusion}

Our study provided new evidence on the value of clinical pharmacists as a member of medical team. Extra pharmaceutical care provided by pharmacist to T2DM outpatients can improve the overall clinical outcomes, such as the levels of FBG, HbA1c, TC, the target attainment rates of $\mathrm{HbAlc}$ and BP, and also medication adherences, which contribute greatly to therapeutic effect. In future studies, a longer and multicenter, prospective, randomized, controlled clinical trial is warranted to confirm our findings.

\section{Acknowledgments}

We would like to acknowledge the assistance of Dr Xueli Zhang (Department of Pharmacy, Zhongda Hospital, School of Medicine, Southeast University, Nanjing, People's Republic of China) during the revision of this paper. This work was supported by the National Natural Science Foundation of China (grant 81102497) and Aosaikang Hospital Foundation of Jiangsu Pharmaceutical Association (grant 201403).

\section{Disclosure}

The authors report no conflicts of interest in this work.

\section{References}

1. International Diabetes Federation. IDF diabetes atlas 7th edition. 2014. Available from: http://www.idf.org/diabetesatlas/5e/Update2014. Accessed December 28, 2016.

2. Hepler CD, Strand LM. Opportunities and responsibilities in pharmaceutical care. Am J Hosp Pharm. 1990;47(3):533-543.

3. Garção JA, Cabrita J. Evaluation of a pharmaceutical care program for hypertensive patients in rural Portugal. J Am Pharm Assoc (Wash). 2002; 42(6):858-864.

4. González-Martin G, Joo I, Sánchez I. Evaluation of the impact of a pharmaceutical care program in children with asthma. Patient Educ Couns. 2003;49(1):13-18.

5. Paulós CP, Nygren CE, Celedón C, Cárcamo CA. Impact of a pharmaceutical care program in a community pharmacy on patients with dyslipidemia. Ann Pharmacother. 2005;39(5):939-943.

6. Sadik A, Yousif M, McElnay JC. Pharmaceutical care of patients with heart failure. Br J Clin Pharmacol. 2005;60(2):183-193.

7. Clark PM, Karagoz T, Apikoglu-Rabus S, Izzettin FV. Effect of pharmacist-led patient education on adherence to tuberculosis treatment. Am J Health Syst Pharm. 2007;64(5):497-505.

8. Al Mazroui NR, Kamal MM, Ghabash NM, Yacout TA, Kole PL, McElnay JC. Influence of pharmaceutical care on health outcomes in patients with type 2 diabetes mellitus. Br J Clin Pharmacol. 2009; 67(5):547-557.

9. Chung N, Rascati K, Lopez D, Jokerst J, Garza A. Impact of a clinical pharmacy program on changes in hemoglobin A1c, diabetes-related hospitalizations, and diabetes-related emergency department visits for patients with diabetes in an underserved population. J Manag Care Spec Pharm. 2014;20(9):914-919.

10. Obreli-Neto PR, Marusic S, Guidoni CM, et al. Economic evaluation of a pharmaceutical care program for elderly diabetic and hypertensive patients in primary health care: a 36-month randomized controlled clinical trial. J Manag Care Spec Pharm. 2015;21(1):66-75.

11. Wei LN, Jing FB, Liu YF, Wand K, Wang YL. Discussion on the model of patient education and pharmaceutical care on a hypertension patient by clinical pharmacists. China Licensed Pharmacists. 2013;9(2):2.

12. Qian NP, Wei RX. Pharmaceutical care for drug treatment provided by clinical pharmacists in Oncology Department. China Pharmacy. 2011;22(10):3.

13. Zheng N, Du YQ, Lin JM. Pharmaceutical care for clinical pharmacists with bronchial asthma and chronic obstructive pulmonary disease patients. Chin J Clin Pharmacol. 2011;27(12):1.

14. Wang B, Guo DH, Liu GY, Tian H. Practice of clinical pharmacist in senile endocrine department. Chin J Drug App Monitor. 2008;5(5):5.

15. Alberti KG, Zimmet PZ. Definition, diagnosis and classification of diabetes mellitus and its complications. Part 1: diagnosis and classification of diabetes mellitus provisional report of a WHO consultation. Diabet Med. 1998;15(7):539-553.

16. Morisky DE, Green LW, Levine DM. Concurrent and predictive validity of a self-reported measure of medication adherence. Med Care. 1986; 24(1):67-74.

17. Miller NH. Compliance with treatment regimens in chronic asymptomatic diseases. Am J Med. 1997;102(2A):43-49. 
18. Schillinger D, Grumbach K, Piette J, et al. Association of health literacy with diabetes outcomes. JAMA. 2002;288(4):475-482.

19. Ciechanowski PS, Katon WJ, Russo JE, Walker EA. The patientprovider relationship: attachment theory and adherence to treatment in diabetes. Am J Psychiatry. 2001;158(1):29-35.

20. Obreli-Neto PR, Guidoni CM, de Oliveira Baldoni A, et al. Effect of a 36-month pharmaceutical care program on pharmacotherapy adherence in elderly diabetic and hypertensive patients. Int J Clin Pharm. 2011;33(4):642-649.

21. Rhee MK, Slocum W, Ziemer DC, et al. Patient adherence improves glycemic control. Diabetes Educ. 2005;31(2):240-250.

22. Rozenfeld Y, Hunt JS, Plauschinat C, Wong KS. Oral antidiabetic medication adherence and glycemic control in managed care. Am J Manag Care. 2008;14(2):71-75.

23. Chiu YW, Chang JM, Lin LI, et al. Adherence to a diabetic care plan provides better glycemic control in ambulatory patients with type 2 diabetes. Kaohsiung J Med Sci. 2009;25(4):184-192.

24. Effect of intensive blood-glucose control with metformin on complications in overweight patients with type 2 diabetes (UKPDS 34). UK Prospective Diabetes Study (UKPDS) Group. Lancet. 1998;352(9131): 854-865.
25. Kahn SE, Steven M, Haffner SM, et al; ADOPT Study Group. Glycemic durability of rosiglitazone, metformin, or glyburide monotherapy. N Engl J Med. 2006;355(23):2427-2443.

26. Borges AP, Guidoni CM, Ferreira LD, de Freitas O, Pereira LR. The pharmaceutical care of patients with type 2 diabetes mellitus. Pharm World Sci. 2010;32(6):730-736.

27. Odegard PS, Goo A, Hummel J, Williams KL, Gray SL. Caring for poorly controlled diabetes mellitus: a randomized pharmacist intervention. Ann Pharmacother. 2005;39(3):433-440.

28. Nichols-English G, Poirier S. Optimizing adherence to pharmaceutical care plans. J Am Pharm Assoc (Wash). 2000;40(4):475-485.

29. Laakso M. Benefits of strict glucose and blood pressure control in type 2 diabetes: lessons from the UK Prospective Diabetes Study. Circulation. 1999;99(4):461-462.

\section{Publish your work in this journal}

Patient Preference and Adherence is an international, peer-reviewed, open access journal that focuses on the growing importance of patient preference and adherence throughout the therapeutic continuum. Patient satisfaction, acceptability, quality of life, compliance, persistence and their role in developing new therapeutic modalities and compounds to optimize clinical outcomes for existing disease states are major areas of interest for the journal. This journal has been accepted for indexing on PubMed Central. The manuscript management system is completely online and includes a very quick and fair peer-review system, which is all easy to use. Visit http://www. dovepress.com/testimonials.php to read real quotes from published authors.

Submit your manuscript here: http://www.dovepress.com/patient-preference-and-adherence-journal 